\title{
Failure of ornithine decarboxylase inhibition to alter small intestinal epithelial repair after transient segmental ischaemia
}

\author{
C GUZMAN, R J MACLEOD, AND J R HAMILTON \\ From the Department of Paediatrics, University of Toronto and The Research Institute, The Hospital for Sick \\ Children, Toronto, Ontario, Canada
}

SUMMARY To evaluate the roles of ornithine decarboxylase (ODC) and polyamines in the regulation of epithelial repair, rabbit mid-small intestine after transient ischaemic villus injury in the presence and absence of DL-difluoromethylornithine (DFMO), an irreversible inhibitor of ODC was studied. Rabbits received $2 \%(w / v)$ DFMO in drinking water for two days before undergoing a sham laparotomy, or a 90 minute mesenteric vascular occlusion of $20 \mathrm{~cm}$ of mid-intestine. DFMO fed and control rabbits were studied four, 24, 72, or 120 hours after this ischaemic intestinal injury. In controls, ischaemic injury caused shortened villi at four hours $(p<0.01)$, diminished mucosal sucrase and alkaline phosphatase activities at 24 hours $(p<0.05)$, but raised ODC $(p<0.001)$ and thymidine kinase $(p<0.01)$ activities at four hours with recovery by 72 hours. DFMO treatment significantly reduced ODC activity at all stages of the experiment and significantly inhibited the rise in activity observed after injury $(p<0 \cdot 01)$. Mucosal concentrations of the polyamines, spermidine and spermine, were similar in the sham operated groups; four hours and 24 hours after ischaemia, they increased in the DFMO animals $(p<0.01)$ but fell $(p<0.05)$ in those that did not receive DFMO. After ischaemic injury, DFMO treatment inhibited ODC but failed to influence recovery of villus structure or enzyme activities in the small intestine. We conclude that ODC and the polyamines, spermidine and spermine, are not key regulators of small intestinal repair after transient ischaemia.

Recent reports have suggested that polyamines are involved in the regulation of the proliferation of cells, including those in the small intestinal epithelium. ${ }^{1-3} \mathrm{~A}$ putative rate limiting enzyme in polyamine synthesis is ornithine decarboxylase (ODC: EC4-1-1-17), ${ }^{+5}$ for which DL-difluoromethylornithine (DFMO) is a specific enzyme activated inhibitor. ${ }^{6}$ To evaluate the importance of polyamines in regulating repair of the small intestinal muscosa after injury, DFMO was given to young rabbits. Then, after inducing transient ischaemic damage in a segment of small intestine, we measured the effect of DFMO on structural and functional recovery from this injury.

${ }^{*}$ Ralston Purina Company (Raleigh, North Carolina, USA).

Address for correspondence: Dr J R Hamilton, Montreal Children's Hospital, 2300 Tupper Street, Montreal, Quebec. Canada H3H 1P3.

Received for publication 22 January 1988.

\section{Methods}

ANIMALS

Sixty New Zealand white rabbits, each weighing approximately $2.5 \mathrm{~kg}$ were allowed to acclimate to our animal facilities for one week before they were studied. Rabbits were housed in individual cages; they had free access to water and conventional rabbit chow* throughout the study. Thirty rabbits were assigned at random to receive DFMO (MDL 71782, Merrell Dow Research Institute, Cincinnati, Ohio) in their drinking water as a $2 \%(\mathrm{w} / \mathrm{v})$ solution for two days before they were subjected to intestinal injury or to a sham laparotomy. Preliminary dose response data of DFMO feeding for two days had shown maximal inhibition of small intestinal mucosal ODC activity at a concentration of DFMO in drinking water of $2 \%$; ornithine decarboxylase was inhibited 
$87,96,96$, and $98 \%$ after ingestion of DFMO at concentrations of $0 \cdot 5,1 \cdot 0,1 \cdot 5$, and $2 \% \mathrm{w} / \mathrm{v}$ respectively. The control treatment group received no additive to their drinking water. Animals from the DFMO treatment group and the control group underwent mesenteric arterial clamping in which the blood supply to a $20 \mathrm{~cm}$ segment of mid-intestine was occluded for 90 minutes under general anaesthesia, using techniques similar to those described for the rat. ${ }^{7}$ In an earlier study, we determined that periods of occlusion exceeding 90 minutes caused irreversible necrosis while shorter periods failed to produce significant mucosal injury. ${ }^{14}$ Mid-intestine was defined as a $20 \mathrm{~cm}$ segment taken at the midpoint between the ligament of Treitz and the ileocaecal junction. Serosal sutures were placed at the proximal and distal ends of this occluded segment for later identification of the injured segment. Sham laparotomy procedure consisted of an abdominal incision and manipulation, but no occlusion of mesenteric vessels. All animals received DFMO-free water after surgery.

Animals were killed four, 24, 72, or 120 hours after operation by parenteral $\mathrm{Na}$ pentobarbital and segments of intestine were taken quickly for microscopic and biochemical studies. For light microscopic measurements, $2 \mathrm{~cm}$ sections were fixed in Bouin's solution and transferred to $70 \%$ alcohol, blocked in paraffin, and stained with haematoxylin-eosin. We measured a minimum of 10 crypt villus units in properly oriented sections, using a calibrated micrometer eyepiece. Sucrase activity was measured in whole mucosal homogenates by the method of Dahlqvist, ${ }^{\times}$alkaline phosphatase by the method of Kelly and Hamilton," and thymidine kinase by a modification" of the method of Klemperer and Haynes."

We measured ornithine decarboxylase by a modification of the technique of Kudlow et al. ${ }^{12}$ Appropriate segments of small intestine after removal were quickly flushed with ice cold saline, and opened. The mucosa was scraped off with a glass slide and homogenised $1: 10(\mathrm{w} / \mathrm{v})$ in ice cold $50 \mathrm{mM}$ Tris- $\mathrm{Cl}$, $5 \mathrm{mM}$ dithiothreitol (DTT), $0 \cdot 1 \mathrm{mM} \mathrm{Na}$ EDTA, $\mathrm{pH}$ $7 \cdot 1$, then quick-frozen in an acetone dry ice bath and stored for up to three days at $-70^{\circ} \mathrm{C}$. After thawing, the homogenate was sonicated for 15 seconds at $100 \mathrm{~W}$ and then centrifuged at $27000 \mathrm{~g}$ for 20 minutes. Aliquots of the supernatant were added to a reaction mixture containing $0 \cdot 5 \mu \mathrm{Ci}$ DL- $\left(1-{ }^{14} \mathrm{C}\right)$ ornithine $(61$ $\mathrm{mCi} / \mathrm{mmol}), 50 \mathrm{mM}$ Tris $\mathrm{Cl}, 5 \mathrm{mM}$ dithiothreitol, $0.25 \mathrm{mM}$ ornithine, and $0.25 \mathrm{mM}$ pyridoxyl-5phosphate, $\mathrm{pH} 7 \cdot 1$, and incubated in stoppered tubes at $37^{\circ} \mathrm{C}$ for one hour in a Dubnoff metabolic incubator. The reaction was stopped by adding $1 \mathrm{ml}$ of $10 \%(\mathrm{w} / \mathrm{v})$ trichloroacetic acid (TCA) and incubated at $37^{\circ} \mathrm{C}$ for an additional hour. The liberated ${ }^{14} \mathrm{CO}_{2}$ was trapped on an impaled filter disc (BD sensitivity disc, Becton-Dickson) that had been spotted with $25 \mu \mathrm{l}$ of a $50 \%$ solution of Protosol (New England Nuclear) in toluene. Blank reactions were stopped before incubation by addition of $1 \mathrm{ml}$ of $10 \%$ TCA and treated as above. The filter discs were transferred to $10 \mathrm{ml}$ Aquasol-2 (New England Nuclear), allowed to sit for 12 hours to quench chemiluminescence, and then counted in a Bscintillation counter. Counts recovered from the reaction blank were substracted from the mean of the counts recovered from the sample. Under these conditions the assay was linear with time and protein concentration. In preliminary experiments we had compared the filter disc method ${ }^{12}$ with the use of suspended wells ${ }^{25}$ and found the discs $30 \%$ more efficient in trapping ${ }^{14} \mathrm{CO}_{2}$ over the same time course. Protein was measured in aliquots of supernatant after TCA precipation. Precipitates were solubilised in $1 \mathrm{~N} \mathrm{NaOH}$. One unit of enzyme activity was defined as one $\mathrm{nmol}{ }^{14} \mathrm{CO}_{2} / \mathrm{h}$ and results expressed as $\mathrm{mU} / \mathrm{mg}$ protein. Activity was measured within three days of sampling as preliminary experiments showed a monotonic decline of ODC activity recovered from small intestinal mucosa stored at $-70^{\circ} \mathrm{C}$ for longer than 3 days. Although the in vivo half life of ornithine decarboxylase is very short ${ }^{323}$ recent work $^{27}$ using partially purified ornithine decarboxylase has confirmed that in vitro activity loss of ornithine decarboxylase was caused by oxidative inactivation which was prevented in the presence of dithiothreitol. Our in vitro incubation contained sufficient dithiothreitol to prevent oxidative inactivation of the enzyme. Furthermore, in preliminary experiments we found unacceptable intra and inter batch assay variability; consistent with other reports ${ }^{25}$ ?h this variability was completely eliminated by first evaporating the labelled ornithine substrate to dryness in a Rotary-Mix evaporator (Buchler Instruments) at $55^{\circ} \mathrm{C}$ and dissolving the residue with $0.01 \mathrm{~N} \mathrm{HCl}$ which was then stored at $4^{\circ} \mathrm{C}$ until it was used. Using this evaporated ornithine, killed (non enzymic) control incubations gave $57 \pm 16 \mathrm{dpm}(n=25)$ with the usual final specific radioactivity used in the assay $(0.5 \mu \mathrm{Ci} / 0.26 \mu \mathrm{mol}$ DL-ornithine).

We used the technique of Wagner et al $^{1.3}$ to measure spermidine and spermine. Putrescine was not measured. Mucosal homogenate was mixed with equal volumes of $0.4 \mathrm{M}$ perchloric acid, centrifuged at $3000 \mathrm{~g}$ for 15 minutes, and the supernatant filtered through Millipore filters $(0.22 \mu \mathrm{m})$. Aliquots of $25 \mu \mathrm{l}$ of the filtered acid extract were injected on the column of an HPLC system. For final calculation the tracings were cut off, weighed, and read, from standard curves of spermidine and spermine. Results are expressed in $\mathrm{n} \mathrm{mol} / \mathrm{mg}$ of extracted protein. 
We obtained ${ }^{14} \mathrm{C}$-ornithine from Amersham (Montreal, Quebec), ${ }^{14} \mathrm{C}$-thymidine from New England Nuclear (Boston, MA), and the remaining reagents from Sigma Chemical (St Louis, MO).

STATISTICAL ANALYSIS

All data were subjected to analysis of variance, and intergroup differences (sham operated, ischaemic injury) were analysed by a one-way analysis of the least significant difference method. Calculations were performed with a Hewlett-Packard 85 microcomputer, and significance was considered to be $\mathrm{p}<0 \cdot 05$.

\section{Results}

\section{LIGHT MICROSCOPY}

Small intestinal mucosal measurements in DFMO treated and control groups before and after ischaemic injury are summarised in Figure 1. In sham operated animals, DFMO treatment had no impact on total crypt villus length. Four hours after ischaemia, mean villus length was significantly reduced compared with shams in both control $(630 \cdot 2(39 \cdot 1) \mu \mathrm{m} v 316.5(40 \cdot 4)$ $\mu \mathrm{m}, \mathrm{p}<0.01)$ and in the DFMO treated $(619.2(37.9)$ $\mu \mathrm{m} v 325.8(25.9) \mu \mathrm{m}, \mathrm{p}<0.01)$ groups. Twenty four hours after ischaemia in non-DFMO fed controls, mean villus length, although $18 \%$ less, was not significantly different from sham operated controls $(p=0.07)$. There were no significant differences in mean villus length between the two groups, at either four hours or 24 hours after ischaemia. The crypts were significantly increased in depth at 24 hours after ischaemia in non-DFMO treated controls (214.5 $(16.1) \mu \mathrm{m} v 140.6(13.3) \mu \mathrm{m}, \mathrm{p}<0.05)$ and in the DFMO-treated rabbits $(169.9(25.1) \mu \mathrm{m} v 119.6$ $(5 \cdot 7) \mu \mathrm{m}, \mathrm{p}<0.05)$. There was no significant difference in the crypt depth between the two treatment groups.

\section{MUCOSAL ENZYMES}

In sham operated animals, DFMO treatment did not affect the specific activities of mucosal sucrase, alkaline phosphatase, or thymidine kinase (Table 1). In non-DFMO fed rabbits, sucrase specific activity was significantly decreased from preinjury levels, 24 hours after ischaemia $(p<0.05)$. At 120 hours, although the mean concentration of sucrase was $26 \%$ less than for sham-operated controls, it was not significantly different from those controls $(p=0 \cdot 25)$. In the DFMO treated group, sucrase specific activity was significantly decreased at both four hours $(p<0.05)$ and 24 hours $(p<0.01)$ in comparison with its sham operated control. At 72 hours the activity had returned to its sham operated value and was not significantly different from the control group.

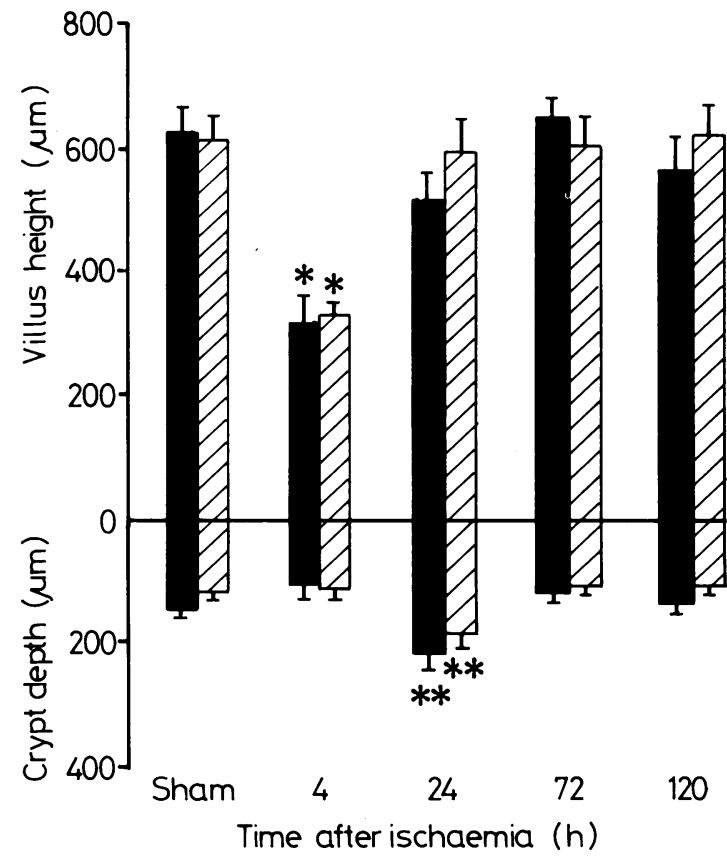

Fig. 1 Light microscopic measurements of rabbit mid-small intestine in control (dark bars) and DFMO fed (shaded bars) after transient ischaemic injury. Number of animals in each group: sham-operated: six, four hours: seven, 24 hours: five, 72 hours: seven, 120 hours: six. ${ }^{*} p<0.01$ compared with sham operated; ${ }^{* *} p<0.05$ compared with sham operated.

Alkaline phosphatase specific activity was significantly decreased at 24 hours $(\mathrm{p}<0.05)$ in comparison with the respective sham operated control in both groups. In the non-DFMO fed group at 72 hours, the activity was greater $(p<0.05)$ than in shams; while in the DFMO group the activity was significantly raised $(p<0.05)$ above sham operated levels at 120 hours after ischaemia. In non-DFMO fed rabbits, four hours after ischaemia, thymidine kinase activity was raised $(p<0 \cdot 01)$. Thymidine kinase was raised $(p<0 \cdot 05) 24$ hours after ischaemia in the DFMO fed rabbits.

Mucosal ornithine decarboxylase (ODC) specific activities in each study group are compared in Figure 2. As expected, DFMO treatment inhibited the enzyme in sham operated rabbits $(0 \cdot 3(0 \cdot 1) \mathrm{mU} / \mathrm{mg} v$ $3.3(0.9) \mathrm{mU} / \mathrm{mg}, \mathrm{p}<0 \cdot 01)$. In non-DFMO treated rabbits, four hours after ischaemia injury, ODC specific activity was raised $15 \times$ compared with the sham operated group $(50 \cdot 0(12.3) \mathrm{mU} / \mathrm{mg} v 3.3(0.9)$ $\mathrm{mU} / \mathrm{mg}, \mathrm{p}<0.001)$ but by 24 hours it had returned to normal. The activity of ornithine decarboxylase increased also in DFMO fed rabbits four hours after ischaemic injury $(1-8 \quad(0.5) \mathrm{mU} / \mathrm{mg} v 0.3 \quad(0 \cdot 1)$ 
Table 1 Small intestinal mucosal enzymes in control and DFMO-fed groups after ischaemic injury or sham-operation

\begin{tabular}{|c|c|c|c|c|c|c|}
\hline \multirow[b]{2}{*}{ Enzyme } & & \multirow[b]{2}{*}{ Sham-operated } & \multicolumn{4}{|c|}{ Time after ischaemia (h) } \\
\hline & & & 4 & 24 & 72 & 120 \\
\hline & $\mathrm{n}$ & 6 & 7 & 5 & 7 & 6 \\
\hline \multirow[t]{2}{*}{ Sucrase (mU/mg) } & Control & $63(13)$ & $39(10)$ & $31(6)^{*}$ & $50(8)$ & $46(6)$ \\
\hline & DFMO & $62(4)$ & $20(4)^{*}$ & $29(6) \div$ & $77(17)$ & $66(6)$ \\
\hline \multirow[t]{2}{*}{ Alkaline Phosphatase ( $\mathrm{mU} / \mathrm{mg}$ ) } & Control & $13(2)$ & $12(1)$ & $8(1)^{*}$ & $22(3)^{*}$ & $13(2)$ \\
\hline & DFMO & $11(2)$ & $11(3)$ & $7(1)^{*}$ & $17(3)$ & $24(2)^{*}$ \\
\hline \multirow{2}{*}{ Thymidine Kinase (U/mg) } & Control & $4 \cdot 8(1)$ & $10 \cdot 6(1)+$ & $6 \cdot 4(2)^{*}$ & $4 \cdot 2(1)$ & $3.2(0.9)$ \\
\hline & DFMO & $4 \cdot 7(0 \cdot 5)$ & $6 \cdot 5(4)$ & $8.4(1)^{*}$ & $4 \cdot 0(0 \cdot 4)^{*}$ & $2 \cdot 9(0 \cdot 4)$ \\
\hline
\end{tabular}

$\mathrm{n}=$ no of animals in each group; ${ }^{*} \mathrm{p}<0.05$ in comparison to sham-operated; $\nmid \mathrm{p}<0.01$ in comparison to sham-operated. Values are expressed as mean (SE).

$\mathrm{mU} / \mathrm{mg}, \mathrm{p}<0 \cdot 05)$ remained raised $(\mathrm{p}<0 \cdot 01)$ above sham operated levels at 24 hours and 72 hours, but returned to normal at 120 hours. In comparison with non-DFMO fed rabbits, however, ornithine decarboxylase activity was less at four hours $(\mathrm{p}<0 \cdot 01), 24$

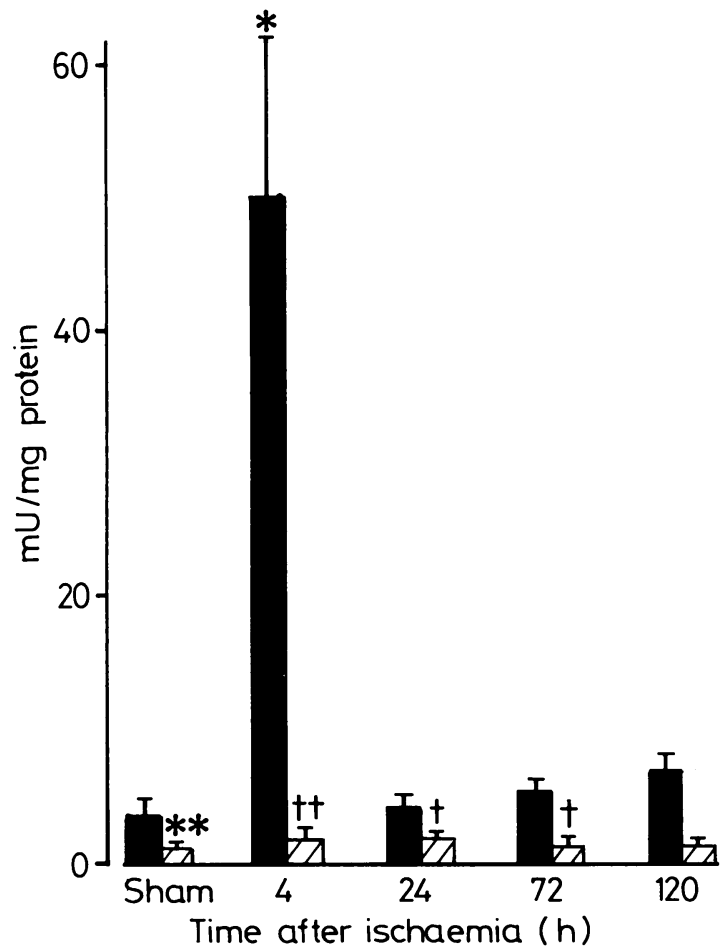

Fig. 2 Ornithine decarboxylase activities in rabbit midsmall intestinal mucosa of a DFMO fed (shaded bars) with non-DFMO fed (dark bars) groups after ischaemic injury. Number of animals in each group: sham-operated: six, four hours: six, 24 hours: six, 72 hours: five, 120 hours: six. ${ }^{*} p<0.001$ compared with sham operated; ${ }^{* *} p<0.01$ compared with non-DFMO fed; $+\dagger p<0.05$ compared with sham-operated, $+p<0.01$ in comparison to sham operated. hours $(p<0 \cdot 05), 72$ hours $(p<0 \cdot 005)$, and at 120 hours $(\mathrm{p}<0 \cdot 005)$.

\section{MUCOSAL POLYAMINES}

In jejunal mucosal homogenates from sham operated rabbits, spermine and spermidine concentrations were not significantly affected by DFMO (Table 2 ). The levels of spermidine decreased $(p<0 \cdot 05)$ at four hours and 24 hours after ischaemia in non-DFMO fed rabbits. In the DFMO fed group, the concentration of spermidine did not change compared with sham operated controls at four hours but it was increased at 24 hours $(p<0 \cdot 05)$. At four hours and 24 hours spermidine concentrations were greater $(p<0 \cdot(05)$ in comparison to the non-DFMO fed groups. The concentration of spermine in the non-DFMO fed group at both four hours and 24 hours after ischaemia was significantly less $(p<0 \cdot 01)$ in comparison to the sham operated control. In the DFMO treated group, spermine concentrations were decreased $(p<0 \cdot 05)$ at four hours but significantly increased $(p<0.01)$ at 24 hours after ischaemic injury. At both four hours $(\mathrm{p}<0.01)$ and 24 hours $(\mathrm{p}<0.001)$ mucosal concen-

Table 2 Polyamine concentrations in rabbit small intestinal mucosal homogenates; control and DFMO-fed groups after sham-operation or ischaemic injury

\begin{tabular}{|c|c|c|c|c|}
\hline \multirow[b]{2}{*}{ Polyamine } & & \multirow[b]{2}{*}{ Sham operated } & \multicolumn{2}{|c|}{ Time after ischaemia $(h)$} \\
\hline & & & 4 & 24 \\
\hline & $\mathrm{n}$ & 3 & 3 & 3 \\
\hline \multirow{2}{*}{$\begin{array}{l}\text { Spermidine } \\
(\mathrm{nmol} / \mathrm{mg})\end{array}$} & Control & $18 \cdot 9(1 \cdot 3)$ & $4 \cdot 6(0 \cdot 9)^{*}$ & $8.4(1.4)^{*}$ \\
\hline & DFMO & $23 \cdot 0(3 \cdot 1)$ & $21 \cdot 7(5 \cdot 6)+$ & $30 \cdot 9(6 \cdot 7)^{* \dagger}$ \\
\hline \multirow{2}{*}{$\begin{array}{l}\text { Spermine } \\
\text { (nmol/mg) }\end{array}$} & Control & $21 \cdot 5(2 \cdot 5)$ & $4 \cdot 0(0.9) \ddagger$ & $7 \cdot 6(0 \cdot 2) \ddagger$ \\
\hline & DFMO & $27 \cdot 0(2 \cdot 0)$ & $17 \cdot 4(2 \cdot 8)^{*} \S$ & $34 \cdot 1(2 \cdot 1) \div \ddagger \S$ \\
\hline
\end{tabular}

$\mathrm{n}=$ no of animals in each group; ${ }^{*} \mathrm{p}<0 \cdot 05$ in comparison to shamoperated; $t p<0 \cdot 05$ in comparison to non-DFMO fed; $\neq p<0 .(01$ in comparison to sham operated; $\$ p<0.01$ in comparison to nonDFMO fed. Values are expressed as mean (SE). 
trations of spermine were greater in DFMO treated groups than in non-DFMO treated group.

\section{Discussion}

In the current experiments 90 minute segmental occlusion of small intestinal vascular flow caused transient structural and functional damage in the villus compartment of the occluded segment, associated with an apparent increased proliferation of the epithelium in the crypts. Previous studies using rabbits in our laboratory,,$^{14}$ and in rats, ${ }^{75}$ yielded similar observations. Villus epithelial cell damage was confirmed in the current experiments by our findings or altered villus morphometry and diminished mucosal sucrase and alkaline phosphate activity. The proliferative response in crypts to this villus cell injury is suggested by the observed increase in mucosal thymidine kinase activity, an enzyme known to be enriched in populations of rapidly dividing cells, ${ }^{16}$ and by the subsequent crypt elongation.

In non-DFMO treated control animals, immediately after experimental ischaemic injury, a 15-fold increase of ornithine decarboxylase specific activity in the mucosa of the injured segment was seen and a subsequent return to basal levels as the proliferative response subsided. In other experimental models in which crypt cell proliferation has been induced, a similar transient ornithine decarboxylase response has been observed. ${ }^{18} 1924$ Indeed, after jejunectomy in the $\mathrm{rat}^{24}$ ornithine decarboxylase increased 170 -fold with subsequent increases in putrescine, spermidine, and spermine. Such data in proliferating intestinal epithelia have supported the concept that polyamines and the rate limiting enzyme in the biosynthetic pathway of polyamines, ornithine decarboxylase are involved in the control of intestinal epithelial renewal. In this study DFMO treatment inhibited the transient marked increase in intestinal mucosal ornithine decarboxylase specific activity after injury by $96 \%$, consistent with other data showing, after DFMO feeding, $65 \%$ to $98 \%$ inhibition of ornithine decarboxylase increases. ${ }^{17}$ In spite of near complete inhibition of ornithine decarboxylase in our DFMOfed rabbits, the concentrations of spermine and spermidine in the small intestine did not diminish as expected but increased after ischaemic injury.

Our data do not support the concept that ornithine decarboxylase is an important regulator of small intestinal epithelial repair in the rabbit. The rise of spermine and spermidine concentrations in the mucosa of DFMO treated rabbits suggests that under our experimental conditions, polyamine uptake by intestinal mocosal cells may have increased. In vitro studies have shown that DFMO and other inhibitors of polyamine synthesis can enhance tissue uptake rates of putrescine or spermidine. ${ }^{1 \times}$ The failure of ischaemic injury to influence tissue spermine and spermidine concentrations in the presence a striking rise of ornithine decarboxylase activity requires further study. In another experimental model in which enhanced crypt cell proliferation, associated with increased ornithine decarboxylase activity, was caused by intraluminal amine infusion, spermine and spermidine levels were not increased. ${ }^{19}$

The current findings suggest also that an alternative pathway for intestine mucosal polyamine production, independent of ornithine decarboxylase activity, may have been activated after ischaemic injury. Polyamine interconversion pathways have recently been shown ${ }^{223}$ and in chicken duodenum putrescine is generated in the presence of DFMO through the combined activity of spermidine $\mathrm{N}$-acetyltransferase and polyamine oxidase..$^{22}$ Our observation of a failure of spermine and spermidine tissue levels to decline in DFMO-fed rabbits after ischaemic injury is consistent with the activation of this alternate pathway but it is clear that high levels of these polyamines in the DFMO group early after ischaemia, did not alter intestinal epithelial repair.

We thank Mr Mahmood Khan for his technical assistance. DL-difluromethylornithine was kindly donated by Dr P. McCann, Merrell Dow Pharmaceuticals Inc, Cincinnati, OH. We are extremely grateful to Dr Margaret Eggo, Banting and Best Department of Medical Research, University of Toronto, for her assistance in pretreating radioactive ornithine facilitating its use in our ornithine decarboxylase assay, and to Dr Fred Keally, Department of Biochemistry, Hospital for Sick Children for his assistance with the spermine and spermidine assays.

This work was supported by a grant from the Medical Research Council of Canada. Dr Guzman received scholarship support from the Anna Bradbury Springer fund, University of Toronto and from the Hospital for Sick Children Foundation during the course of these studies.

\section{References}

1 Janne J, Poso H, Raina A. Polyamines in rapid growth and cancer. Biochem Biophys Acta 1978; 473: 241-93.

2 McCann P. Regulation of ornithine decarboxylase in eukaryotes. In: Gauges JM, ed. Polyamines in Biomedical Research. New York: Wiley, 1980: 109-24.

3 Tabor CW, Tabor H. Polyamines. Annu Rev Biochem 1984; 53: 749-90.

4 Fillingame RH, Jorstad CM, Morris DR. Increased cellular levels of spermidine or spermine are required for optimal DNA synthesis in lymphocytes activated by 
concanavalin A. Proc Natl Acad Sci USA 1975; 72: 4042-5.

5 Luk GD, Baylin SB. Inhibition of epithelial DNA synthesis and adaptive hyperplasia after jejunectomy in the rat by suppression of polyamine biosynthesis. J Clin Invest 1984; 74: 698-704.

6 Metcalf BW, Bey P, Dauzin C, Jung MJ, Casara P, Vevert JP. Catalytic irreversible inhibition of mammalian ornithine decarboxylase (E.C.4.1.1.17) by substrate and product analogs. J Am Chem Soc 1978; 100: 2551-3.

7 Menge H, Robinson WL. Early phase of jejunal regeneration after short-term ischaemia in the rat. Lab Invest 1979; 40: 25-31.

8 Dahlqvist $H$. Method for assay of intestinal disaccharidases. Anal Biochem 1966; 22: 99-107.

9 Kelly MH, Hamilton JR. A microtechnique for the assay of intestinal alkaline phosphatase. Results in normal children and in children with celiac disease. Clin Biochem 1970; 3: 33-43.

10 Kerzner B, Kelly MH, Gall DG, Hamilton JR. Transmissible gastroenteritis. Na transport and the intestinal epithelium during the course of viral enteritis. Gastroenterology 1977; 72: 457-61.

11 Klemperer HG, Haynes GR. Thymidine kinase in rat liver during development. Biochem J 1960; 108: 541-6.

12 Kudlow JE, Raw PA, Gutmann NS, Schimmer BP, Burrow GN. Regulation of ODC-ase activity by corticotropin in adrenal cortical tumor cell clones: Role of cyclic AMP and cyclic AMP-dependent protein kinase. Proc Natl Acad Sci USA 1980; 77: 2767-71.

13 Wagner $\mathrm{J}$, Calvarie $\mathrm{N}$, Danzin $\mathrm{C}$. A rapid highperformance liquid chromatographic procedure for the simultaneous determination of Methionine, Ethionine, S-Adenosylmethionine, S-Adenosylethionine, and the natural polyamines in rat tissues. Anal Biochem 1984; 140: $108-16$.

14 Guzman C, Hamilton JR. Intestinal repair in chronic protein-calorie malnutrition. Pediatr Res 1986; 20: 1301-4.

15 Rijke R, Hanson WR, Plaisier HM, Osborne JW. The effect of ischemic villus cell damage on crypt cell proliferation in the small intestine. Gastroenterology 1976; 71: 786-92.

16 Weiser MM. Intestinal epithelial cell surface membrane glycoprotein synthesis. An indicator of cell differentiation. J Biol Chem 1973; 248: 2536-41.

17 Luk GD, Marton LJ, Baylin SB. Ornithine decarboxylase is important in intestinal mucosal maturation and recovery from injury in rats. Science 1980; 210: 195-8.

18 Seidel ER, Haddox MK, Johnson LR. Polyamines in the response to intestinal obstruction. Am J Physiol 1984; 246: G649-53

19 Seidel ER, Haddox MK, Johnson LR. Ileal mucosal growth during intraluminal infusion of ethylamine or putrescine. Am J Physiol 1985; 249: G434-38.

20 Janne J, Alhonen-Hongisto L, Seppanen P, Shmes M. Use of polyamine antimetabolities in experimental tumors and in human leukaemia. Med Biol 1981; 59: $448-57$

21 Rinchart CA, Chen KY. Characterization of the polyamine transport system in mouse neuroblastoma cells. J Biol Chem 1984; 259: 4750-6.

22 Shinki T, Kadofukus T, Sate T, Suda T. Spermidine N1acetyltransferase has a larger role than ornithine decarboxylase in 125 -dehydroxy vitamin D3-induced putrescine synthesis. J Biol Chem 1986; 261: 11712-6.

23 Pegg AE. Recent advances in the biochemistry of polyamines in eukaryotes. Biochem J 1986; 234: 249-62.

24 Luk GD, Baylin SB. Polyamines and intestinal growth increased polyamine biosynthesis after jejunectomy. Am J Physiol 1983; 245: G656-60.

25 Janne J, Williams-Ashman HG. On the purification of L-ornithine decarboxylase from rat prostrate and effects of thiol compounds on the enzyme. J Biol Chem 1971; 246: $1725-32$.

26 Malo C, Qureshi I, Letarte J. Postnatal maturation of enterocytes in sparse-fur mutant mice. Am J Physiol 1986; 250: G177-84.

27 Seely JE, Persson L, Sertich GJ, Pegg AE. Comparison of otnithine decarboxylase from rat liver, rat hepatoma, and mouse kidney. Biochem J 1985; 226: 577-86. 